of crying during measured time periods. Since crying time was quite variable, many more infants would have been required for us to have established with certainty that there was no difference between the feeds. The similarity, however, in spontaneous feed intake on the two formulas serves as a cross check on the cry times, and it is highly unlikely that the older formula was perceived as more satisfying than the newer, more highly adapted one, in spite of its greater concentration of energy, protein, and sodium and its starch content. Since change in feed intake was found to be negatively correlated with change in crying time it is possible that infants preferred the taste of one formula to the other (though there was no consistent favourite). The only property of feeds which has definitely been shown to influence the intake of young infants remains their sweetness. ${ }^{2}$

Since the infants consumed virtually identical volumes of the two formulas, their intake of energy, protein, and sodium was greater on the richer formula. Although there is no evidence that harm will occur at this volume of intake, there is an authoritative view that the young formula fed infants should receive a feed as near as possible in composition to human milk, ${ }^{3}$ particularly in respect of protein, ${ }^{4}$ since it is difficult to exclude the possibility of an occasional case of hypernatraemic dehydration on formulas with higher protein and salt content. The temptation to change to a richer formula in infants with 'feeding problems' should therefore be resisted since these formulas are no more satisfying, and attempts should be made to try to identify other causes of distress in the infant. It is possible, however, that the older infant of 4 to 6 months may find a richer formula more to his taste, though evidence for this is lacking.

Milupa Ltd provided the formulas and the funding for $\mathrm{C} \mathrm{W}$, as well as logistical assistance with running the study.

\section{References}

1 Jones RAK, Belsey EM. Common mistakes in infant feeding: a survey from a London borough. Br Med J 1978,ii:112-5.

${ }^{2}$ Nisbett RE, Gurwitz SB. Weight, sex and eating behaviour of human newborns. J Comp Physiol Psychol 1970;73:215-25.

${ }^{3}$ ESPGAN committee on nutrition. Guidelines on infant nutrition. III Recommendations for infant feeding. Acta Paediatr Scand [Suppl] 1982;302:6.

${ }^{4}$ Moro G, Minoli I, Raiha N. Milk protein quantity in the term infant; metabolic responses and effects on growth. Proceedings of XVII annual meeting of the European Society for Paediatric Gastroenterology and Nutrition, 1984. Pediatr Res 1984; 18:1051.

Correspondence to $\mathrm{Dr} \mathrm{O}$ G Brooke, Department of Child Health, St George's Hospital Medical School, Cranmer Terrace, London SW17 0RE.

Received 4 February 1985

\title{
Acid base balance in blood and cerebrospinal fluid
}

\author{
Y HOROVITZ, I TAL, AND A KEYNAN \\ Department of Pediatrics A, Central Emek Hospital, Afula, Israel
}

SUMMARY Thirty four infants were studied; 21 with acute gastroenteritis, dehydration, and metabolic acidosis and 13 who served as controls. All infants with metabolic acidosis and without neurological signs had a normal to near normal cerebrospinal fluid acid base balance, but five with metabolic acidosis and severe neurological signs had cerebrospinal fluid acid base disequilibrium. Acute metabolic acidosis in infants may lead to cerebrospinal fluid acid base imbalance causing cerebral dysfunction.

Acute gastroenteritis in infancy is often accompanied by metabolic acidosis. Some acidotic infants may manifest neurological disturbances without concomitant electrolyte pathology. We suggest that only when the cerebrospinal fluid balance is disturbed will neurological signs occur.

\section{Patients and methods}

Thirty four infants, divided into two groups ( $\mathrm{A}$ and B), whose ages were between 1 month and 16 months were included in this study. Group A consisted of 21 infants admitted to hospital with acute gastroenteritis. All were mildly to severely dehydrated (5\% to $7 \%$ weight loss), with normal serum electrolyte values. We excluded from the study those with diseases other than acute gastroenteritis, those with known neurological conditions, infants with a history of convulsions, and all infants with a history of birth trauma or low birthweight, or both. 
Group B consisted of 13 infants, and served as a control. Their ages were between 1 month and 14 months, and they had been admitted with suspected meningitis, which had been ruled out during their hospital stay. All were within normal limits. None of these infants were severely ill; they were febrile, and probably had minor viral infections. All were discharged within 72 hours.

On admission all infants were assessed for:

(1) Disturbance of consciousness, convulsions, muscle tone, and tendon and superficial reflexes.

(2) Venous blood was examined to determine sodium, potassium, calcium, phosphate, magnesium, blood urea nitrogen, and glucose values. All infants with one or more abnormal result were excluded.

(3) Capillary blood samples were taken from the prewarmed heel for blood gas analysis. The results were plotted on the Siggard-Anderson nomogram. ${ }^{1}$

(4) One ml of cerebrospinal fluid was drawn from the subarachnoid space by lumbar puncture. Bloody taps were excluded. The cerebrospinal fluid was then examined for $\mathrm{pH}, \mathrm{PcO}_{2}, \mathrm{BE}$, Act., bicarbonate, exactly as the capillary blood sample according to the Astrup method. Both samples were examined within 10 minutes.

All blood and cerebrospinal fluid analysis results were checked mathematically by the HendersonHasselbalch equation. ${ }^{2}$ All values were corrected to body temperature. The results were evaluated using the Student's $t$ test.

\section{Results}

The results of blood and cerebrospinal fluid gas analysis for the 13 infants in group B are shown in the Table. In all the infants the $\mathrm{pH}$ value of the cerebrospinal fluid was lower than that in bloodblood $\mathrm{pH}$ was mean (SD) $7.393(0.034)$ while cerebrospinal fluid $\mathrm{pH}$ was $7.328(0.033)(\mathrm{P}<0.05)$. The $\mathrm{PCO}_{2}$ value was higher in cerebrospinal fluid than in blood-mean (SD), $42.15(8.06) \mathrm{mm} \mathrm{Hg}$ and $36.53(3.92) \mathrm{mm} \mathrm{Hg}$ respectively $(\mathrm{P}<0.001)$. The bicarbonate value in blood was mean (SD), 21.67 $(2.46)$ while in cerebrospinal fluid it was 21.05 (1.01) (P was not significant).

Sixteen of the 21 infants in group A (group A1) had gastroenteritis without neurological signs (Table). Their blood $\mathrm{pH}$ was mean (SD), 7.259 $(0.066)$ while the corresponding values for cerebrospinal fluid were $7.343(0.035)(\mathrm{P}<0.001)$. The $\mathrm{PCO}_{2}$ in blood was mean (SD), $28.98(7.45) \mathrm{mm} \mathrm{Hg}$ and in cerebrospinal fluid 30.09 (11.12) (not significant). The blood bicarbonate concentration was mean (SD), $12.78(4.36) \mathrm{mmol} / \mathrm{l}$ and the value in cerebrospinal fluid was $15.56(4.89)$ (not significant).

In the five infants in group A2 who had overt neurological signs such as coma or convulsions, the blood $\mathrm{pH}$ was mean (SD), $7.226(0 \cdot 105)$ and the value in cerebrospinal fluid $7.244(0.029)$ (not significant). Blood $\mathrm{PCO}_{2}$ in these five was mean (SD), $30.80(2.78) \mathrm{mm} \mathrm{Hg}$, while in cerebrospinal fluid it was $33.30(5.04)$ (not significant). The blood concentration of bicarbonate was mean (SD), 12.62 (3.67) and that in cerebrospinal fluid was 13.82 (3.65) $\mathrm{mmol} / \mathrm{l}$ (not significant).

When comparing the mean blood and cerebrospinal fluid $\mathrm{pH}$ values of control group infants with those of infants with gastroenteritis who had neurological signs, there was a significant difference $(\mathrm{P}<0 \cdot 001)$.

\section{Discussion}

The acid base metabolism of the cerebral compartment may influence cerebral function to a considerable degree. ${ }^{2}$ Studies of the relation between blood $\mathrm{pH}$ and cerebrospinal fluid acid base status in human beings are scanty and incomplete. There are reports that state that during convulsions the $\mathrm{pH}$ in cerebrospinal fluid decreases as a result of accumulation of lactic acid. ${ }^{3}$ Few published reports deal

Table Gas analysis in blood and cerebrospinal fluid (CSF) in infants with gastroenteritis (group A) and a control group (group B). (Values mean (SD))

\begin{tabular}{|c|c|c|c|c|c|c|c|}
\hline & & \multicolumn{2}{|l|}{$p H$} & \multicolumn{2}{|c|}{$\mathrm{PCO}_{2}(\mathrm{~mm} \mathrm{Hg})$} & \multicolumn{2}{|c|}{ Bicarbonate (mmolll) } \\
\hline & & Blood & CSF & Blood & $\operatorname{CSF}$ & Blood & $C S F$ \\
\hline \multirow[t]{2}{*}{$\begin{array}{r}\text { Group } A \\
(n=21)\end{array}$} & $1^{*}$ & $\begin{array}{r}7.259(0.066) \\
P<\end{array}$ & $\begin{array}{l}7 \cdot 343(0 \cdot 035) \\
001\end{array}$ & $28.93(7 \cdot 54)$ & $30 \cdot 09(11 \cdot 12)$ & $12 \cdot 78(4 \cdot 36)$ & $15 \cdot 56(4 \cdot 88)$ \\
\hline & $2^{*}$ & \multicolumn{2}{|c|}{ NS } & $30 \cdot 80(2 \cdot 78)$ & $33 \cdot 30(5 \cdot 04)$ & $12 \cdot 62(3 \cdot 67)$ & $13 \cdot 82(3 \cdot 65)$ \\
\hline $\begin{array}{r}\text { Group B } \\
(n=13)\end{array}$ & & $\begin{array}{r}7.392(0.034) \\
\mathrm{P}\end{array}$ & $\begin{array}{l}7 \cdot 328(0.033) \\
.05\end{array}$ & $\begin{array}{r}36.53(3.92) \\
\mathrm{P}\end{array}$ & $\begin{array}{l}42 \cdot 15(8 \cdot 06) \\
01\end{array}$ & $21.67(2 \cdot 46)$ & $21.05(1.01)$ \\
\hline
\end{tabular}

${ }^{*}$ Group $A 1=16$ infants with no neurological signs; group $A 2$ infants with neurological signs. 
with infants. ${ }^{45}$ Our results showed a cerebrospinal fluid $\mathrm{pH}$ lower than the blood $\mathrm{pH}$ in healthy infants; higher $\mathrm{PCO}_{2}$ values in cerebrospinal fluid than in blood; and a lower concentration of bicarbonate in cerebrospinal fluid than in blood, which is in accordance with previous reports. ${ }^{4-6}$ Most infants with metabolic acidosis had normal or near normal $\mathrm{pH}$ in cerebrospinal fluid. It is reasonable to assume that the reason for this phenomenon is twofold-the lower value of $\mathrm{PCO}_{2}$ and the higher concentrations of bicarbonate in the cerebrospinal fluid of those infants suffering from metabolic acidosis, compared with infants in the control group. This shows that even in the presence of an acute metabolic acidosis with a low blood $\mathrm{pH}$ the cerebrospinal fluid often succeeds in maintaining a near normal $\mathrm{pH}$ value. ${ }^{78}$

The infants with an acute metabolic acidosis in their blood showed neurological signs and symptoms (coma, convulsions, or both) confirming the assumption that metabolic acidosis in blood can lead to a cerebrospinal fluid acid base disequilibrium, thus causing cerebral dysfunction. During the acute plasma metabolic acidosis the $\mathrm{pH}$ in cerebrospinal fluid may shift in the opposite direction from the extracellular $\mathrm{pH}$. This 'paradoxical' response seems to be related to the free permeability of the meningeal barrier to carbon dioxide gas, while hydrogen and bicarbonate equilibration across the membrane takes place slowly. Another hypothesis is that a child with any neurological sign such as convulsions may have an impaired ability to control $\mathrm{pH}$ in cerebrospinal fluid. We have not included such infants as our study was intended to emphasise the fact that acute metabolic acidosis caused by gastroenteritis can, by itselt, cause a disequilibrium in the cerebrospinal fluid $\mathrm{pH}$ with the emergence of a neurological disorder.

The results of the present work stress the importance of the careful correction of the metabolic acidosis in infants suffering from acute gastroenteritis and showing neurological signs. A rapid infusion of sodium bicarbonate may correct the blood $\mathrm{pH}$ but as a result the $\mathrm{PCO}_{2}$ in cerebrospinal fluid may rise, lowering the $\mathrm{pH}$ and endangering brain function.

\footnotetext{
References

I Siggard-Andersen O. Acid-base status of blood. J Clin Lab Invest 1963;70:1-34(Supplement).

${ }^{2}$ Posner JB, Plum F. Spinal fluid $\mathrm{pH}$ and neurological symptoms in systemic acidosis. N Engl J Med 1967;277:605-13.

${ }^{3}$ Beresford HR, Posner JB, Plum F. Changes in brain lactate during induced cerebral scizures. Arch Neurol 1969;20:243.

${ }^{4}$ Krauss AN, Thibcault DW, Auld PA. Acid-base balance in cerebro-spinal fluid of newborn infants. Biol Neonate 1972;21: 25-34.

5 Albert MS, Rahill WJ, Vega L, Winters RW. Acid-base changes in CSF of infants with metabolic acidosis. $N$ Engl J Med 1966;274:719-21.

6 Manfredi F. Acid-base relations between serum and CSF in man under normal and abnormal conditions. J Lab Clin Med 1962;59:128-36.

${ }^{7}$ Posner JB, Plum F. Protection of CSF pH and of the brain function during severe metabolic acidosis. Trans Am Neurol Assoc 1966;91:38-43.

${ }^{8}$ Siesjo BK, Kjallquist A. A new theory for the regulation of the extra-cellular $\mathrm{pH}$ in the brain. Scand J Clin Lab Invest 1969;24:1-9.
}

Correspondence to Dr Y Horovitz, Pediatric Department A, Central Emek Hospital, Afula 18101, Israel.

Received 4 December 1984

\section{Raised intracranial pressure not detected by ultrasound}

\section{W PILLING AND R E CUDMORE}

\section{Departments of Radiology and Surgery, Alder Hey Children's Hospital, Liverpool}

SUMmaRY Two patients with raised intracranial pressure responding to ventriculoperitoneal shunting are described in whom ultrasound failed to show dilated ventricles. The importance of not equating absence of ventricular dilatation with normal pressure and ventricular dilatation with high pressure is emphasised.

Ultrasound of the skull has become a routine examination in the neonate and infant with increasing head circumference or signs of raised intracra- nial pressure, or both. The technique has come to be relied upon for assessment of ventricular size, with timing of insertion of a shunt being strongly influenced by the size of the ventricles.

We report two patients without ventricular dilatation who had clinical signs of raised intracranial pressure and raised pressure on ventricular tap. In both relief of symptoms and signs followed ventriculoperitoneal shunting.

\section{Case reports}

Case 1. A thoracic meningocele was diagnosed at 